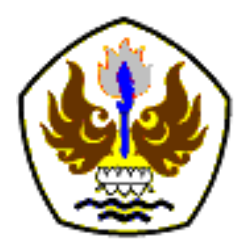

INFOMATEK

Volume 20 Nomor 2 Desember 2018

\title{
ANALISIS KEBOCORAN BELOKAN PIPA EVAPORATOR PADA HRSG AKIBAT BEBAN TERMAL
}

\author{
Aa Santosa*, Iwan Nugraha \\ Program Teknik Mesin \\ Fakultas Teknik - Universitas Singaperbangsa Karawang
}

\begin{abstract}
Abstrak: HEAT RECOVERY STEAM GENERATOR yang digunakan pada system Pembangkit Listrik Tenaga Gas uap di suatu pembangkit listrik mengalami masalah yang sama setelah beroprasi dalam jangka waktu tertentu. Pipa-pipa LP evaporator selalu mengalami kebocoran di lokasi yang sama dan kejadiannya selalu berulang-ulang walaupun sudah dilakukan perbaikan pada lokasi kebocoran tersebut. Pipa-pipa tersebut berfungsi untuk menyerap panas dari gas panas untuk memproduksi uap yang kemudian disalurkan ke system turbin uap. Lama kelamaan pipa-pipa tersebut mengalami penumpukan kotoran sehingga menutupi bagian permukaannya yang mengakibatkan laju perpindahan panas tidak optimal kotoran yang menempel pada pipa tersebut cenderung lebih banyak di sisi sebelah barat dari HRSG dibandingkan dengan sebelah timur, keadaan tersebut hampir terjadi di semua unit HRSG di perusahaan pembangkit yang ditinjau. Analisa aliran dilakukan untuk mengetahui kondisi laju alirangas panas di dalam HRSG. HRSG dimodelkan dalam bentuk gambar SolidWork dengan skala 1:1 kemudian disimulasikan menggunakan Software Computational fluid dynamic $(C F D)$. Dari hasil analisis CFD terjadi ketidakseragaman aliran gas panas pada HRSG antara sisi sebelah timur dan sebelah barat, aliran sebelah timur cenderung lebih cepat dibanding sebelah barat sehingga terjadi penumpukan kotoran pada bagian sebelah barat. Hasil pengukuran juga menunjukan adanya ketidakseragaman kecepatan aliran antara sisi sebelah barat dan sisi sebelah timur. Hasil sebanding antara proses pengukuran dan simulasi menunjukan kecepatan hasil analisis yang baik. Rekomendasi yang lainnya supaya menjaga fleksibilitas pipa-pipa header untuk mengantisipasi terjadinya ekspansi termal yang bisa mengakibatkan kebocoran pada pipa tersebut.
\end{abstract}

Kata kunci: Evaporator, Fleksibelitas, HRSG

\section{PENDAHULUAN}

Pembangkit Listrik Tenaga Gas Uap (PLTGU), merupakan gabungan antara Pembangkit Listrik Tenaga Gas (PLTG) dengan Pembangkit Listrik Tenaga Uap (PLTU). PLTU beroperasi dengan cara memanfaatkan gas

\footnotetext{
*) aa_santosa72@yahoo.com

Pertama diterima : 6 Agustus 2018

Direvisi : 4 November 2018

Disetujui untuk publikasi:5 November 2018
}

buang dari PLTG bertemperatur $484^{\circ} \mathrm{C}$ digunakan untuk menghasilkan uap yang kemudian digunakan sebagai fluida kerja untuk memutarkan Turbin. Bagian yang digunakan untuk menghasilkan uap tersebut adalah Heat Recovary Steam Generator. Bagian (HRSG). HRSG ini terdiri dari Superhaeater, Evaporator dan Economizer, termasuk dua tingkat Evaporator yaitu $H P$ 
Evaporator dan LP Evaporator (ASME, 1996 [1], API Standard 661, 1997 [2], Arismunandar, 1982 [3]).

PLTGU yang ada di Indonesia ada yang telah beroperasi selama lebih dari 20 tahun. kerusakan yang terjadi adalah berupa kebocoran pada pipa HRSG di daerah $L P$ Evaporator. Kerusakan ini terjadi pada ke tiga unit HRSG yang serupa (Kannapan, 1986 [4]). Pipa-pipa Evaporator dihubungkan dengan pipa besar (header) yang membentang dari Barat ke Timur sepanjang 12 meter. Kerusakan diawali dengan terlihatnya kotoran berupa scale (deposit) yang menempel pada pipa HRSG di daerah LP Evaporator, Selain kotoran, terlihat pada bagian pipa tersebut adanya korosi yang bisa mengakibatkan terhambatnya laju perpindahan panas dari gas buang ke pipa LP Evaporator (Electric General, 1997 [5], Dietzel, 1994 [6]), (Kays, 1964 [7]).

Dalam kajian ini penelitian difokuskan pada daerah HRSG yang mengalami kerusakan yang paling sering terjadi. Berdasarkan informasi yang berhasil dikumpulkam dari PLTGU yang diamati, kerusakan yang paling sering terjadi adalah kebocoran pada pipapipa $L P$ Evaporator. Selama ini penanganan yang dilakukan untuk mengatasi masalah ini adalah dengan memotong bagian yang bocor dan menggantinya dengan pipa baru yang sejenis (Munson, 2002 [8]), (Burlian, 2013 [9]). Salah satu usaha yang akan ditempuh dalam penelitian ini adalah mencari penyebab dari kerusakan tersebut dan mencari solusinya agar masa operasi HRSG di antara jadwal maintenance menjadi lebih panjang.

Dilakukan simulasi dengan menggunakan bantuan komputer untuk tegangan yang terjadi pada belokan pipa LP Evaporator tersebut.

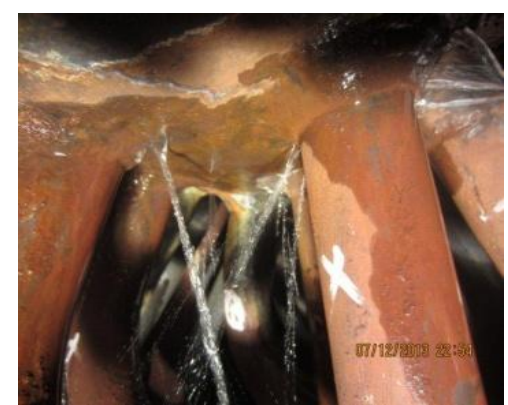

Gambar 1

Bocor pada sambungan pipa LP Evaporator

\section{METODOLOGI}

Untuk mencapai tujuan dari penelitian ini diperlukan rancangan penelitian baik secara experimen maupun secara teoritis. Penelitian diawali dengan studi literatur dan survey lapangan tentang masalah-masalah yang sering timbul didalam HRSG, mempelajari teknik-teknik perbaikan, mengamati kondisikondisi operasi HRSG. Untuk meperkuat hasil 
analisis dilakukan pengukuran distribusi kecepatan aliran sebelum HRSG yaitu didalam bagian yang menghubungkan saluran gas buang dengan HRSG (Homan, 1988 [10]), (Abdurachim, 2002 [11]). Analisis aliran gas asap dilakukan dengan menggunakan bantuan computer (Pridyatama, 2014 [12]).

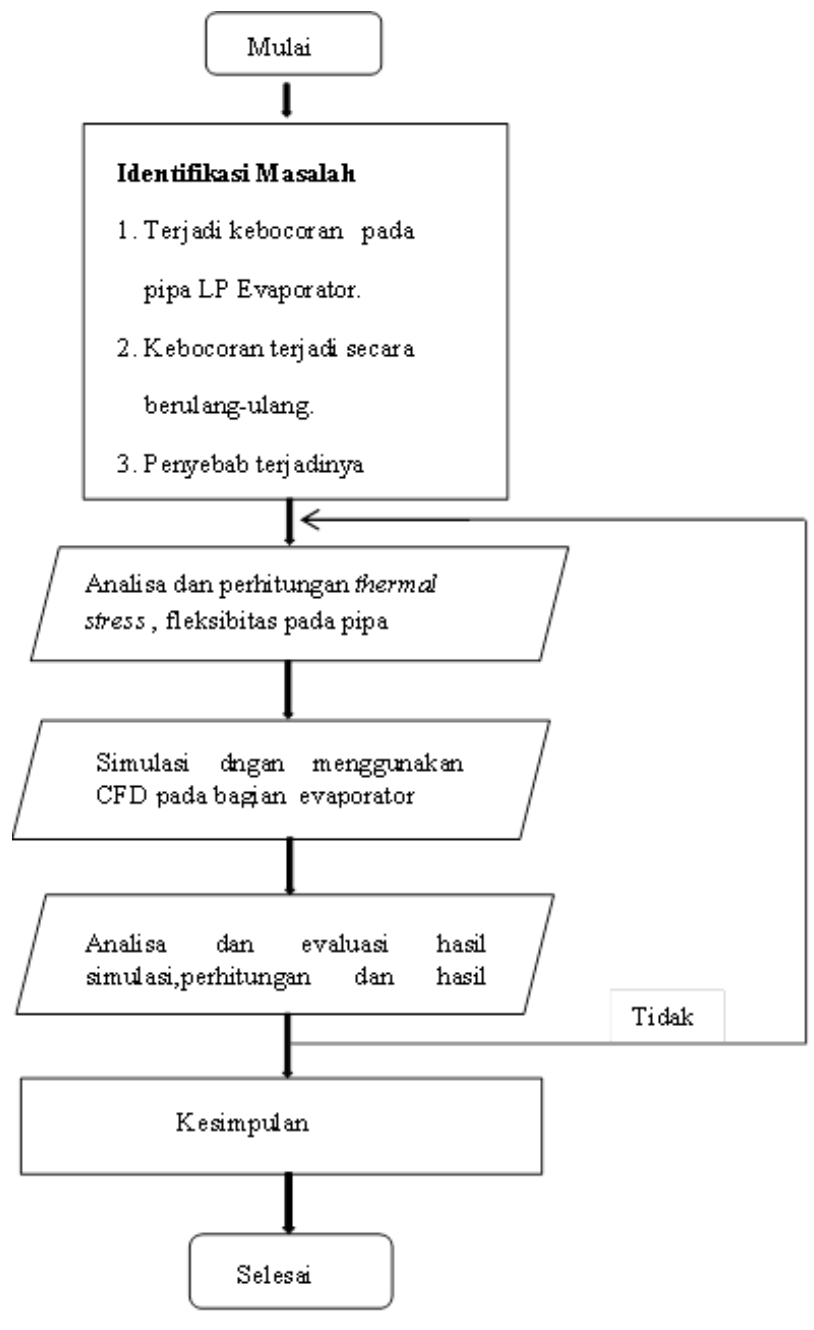

Gambar 2

Flowchart pene anlisis kebocoran belokan pipa evaporator pada HRSG akibat beban termal

\section{ANALISIS DAN PEMBAHASAN}

1. Analisis Perhitungan Termal

Rangkuman proses perhitungan koefisien konveksi rata-rata pada pipa-pipa $L P$ Evaporator ditunjukkan pada Tabel 1.

Tabel 1

Rangkuman proses perhitungan koefisien rata-rata eksternal pipa.

\begin{tabular}{|c|c|c|c|}
\hline & \multicolumn{2}{|c|}{ Kondisi pipa } & \multirow{2}{*}{ Satuan } \\
\hline & Bersih & Kotor & \\
\hline $\begin{array}{l}\text { Laju alir massa } \\
(m)\end{array}$ & \multicolumn{2}{|c|}{87,5} & $\mathrm{~kg} / \mathrm{s}$ \\
\hline $\begin{array}{c}\text { Area } \\
\text { perpindahan } \\
\text { panas }(A)\end{array}$ & 10.179 & 4.590 & $\mathrm{~m}^{2}$ \\
\hline $\begin{array}{l}\text { Frontal area } \\
\qquad\left(A_{f r}\right)\end{array}$ & \multicolumn{2}{|c|}{107,86} & $\mathrm{~m}^{2}$ \\
\hline $\begin{array}{l}\text { Diameter luar } \\
\operatorname{pipa}\left(d_{o}\right)\end{array}$ & 44,5 & 53,5 & $\mathrm{~mm}$ \\
\hline Luas pipa $\left(A_{t}\right)$ & 998,5 & $\begin{array}{c}1.200, \\
5\end{array}$ & $\mathrm{~m}^{2}$ \\
\hline Luas sirip & 9180,5 & $\begin{array}{c}3.389, \\
7\end{array}$ & $\mathrm{~m}^{2}$ \\
\hline $\begin{array}{l}\text { Rasio area } \\
\text { aliran } \\
\text { bebas/area } \\
\text { frontal }(\sigma)\end{array}$ & 0,482 & 0,388 & - \\
\hline $\begin{array}{l}\text { Laju alir massa } \\
\text { maksimum }(G)\end{array}$ & 1,683 & 2,090 & $\mathrm{~kg} / \mathrm{s} \cdot \mathrm{m}^{2}$ \\
\hline $\begin{array}{c}\text { Densitas gas } \\
\text { panas }(\rho)\end{array}$ & \multicolumn{2}{|c|}{0,750} & $\mathrm{~kg} / \mathrm{m}^{3}$ \\
\hline $\begin{array}{c}\text { Koefisien } \\
\text { viskositas gas }\end{array}$ & \multicolumn{2}{|c|}{$26,4 \times 10^{-6}$} & $\mathrm{Ns} / \mathrm{m}^{2}$ \\
\hline
\end{tabular}




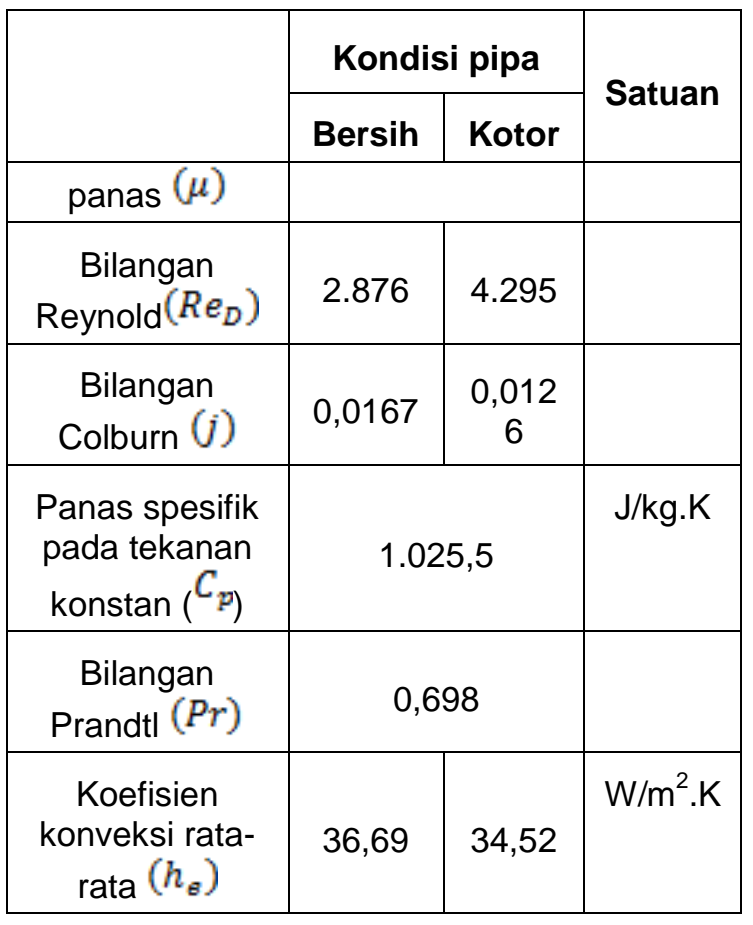

\section{Analisis hasil Elbow pipa LP Evaporator} yang mengalami kebocoran.

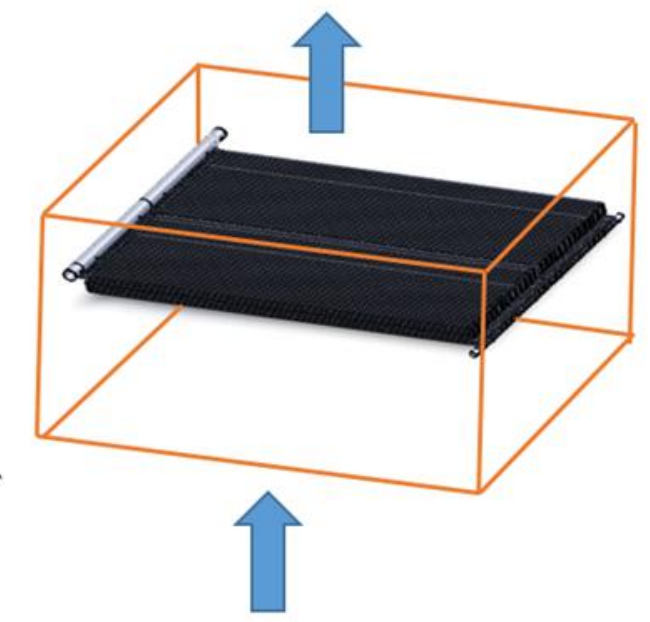

Gambar 3

Gas keluar pada pipa LP Evaporator

\section{Kondisi batas untuk gas masuk}

1. Temperatur masuk $280^{\circ} \mathrm{C}$.

2. massa jenis gas masuk $0,459 / \mathrm{m}^{3}$.

3. Kecepatan gas masuk $10,26 \mathrm{~m} / \mathrm{s}$.

4. Jenis aliran turbulen.

5. Viskositas udara $3,63 \times 10^{-5} \mathrm{~kg} / \mathrm{m}$.s.

\section{KESIMPULAN}

Setelah melakukan perhitungan pada pipa bagian barat maupun bagian timur kemudian dibandingkan dengan hasil simulasi dengan menggunakan CFD, maka kesimpulan yang bisa dihasilkan adalah sebagai berikut:

1. Analisis besar koefisien konveksi pada sisi pipa-pipa yang permukaannya bersih atau tidak tertutup deposit sebesar 36,69 W/m2.K sedangkan pada sisi pipa-pipa yang separuh permukaannya tertutup deposit sebesar $34,52 \mathrm{~W} / \mathrm{m} 2 . \mathrm{K}$

2. Dari hasil perhitungan fleksibilitas pipa didapat nilai fleksibilitas pipa sebelah timur lebih besar dari 0,03 yaitu 0,04. Pipa sebelah barat nilai fleksibilitasnya mencapai 0,009. Penyebab nilai fleksibilitas yang berbeda karena temperatur pipa di sebelah timur lebih besar dibandingkan dengan pipa sebelah barat. Temperatur pipa 
sebelah timur mencapai $280^{\circ} \mathrm{C}$, sedangkan temperature pipa sebelah barat $90^{\circ} \mathrm{C}$.

3. Fleksibilitas pipa antara bagian sebelah timur dan barat tidak sama, bagian sebelah timur fleksibiltasnya mencapai 0,04 selebih besar dari angka yang distandarkan yaitu sebesar 0,03. Maka terjadi pemuaian pada pipa tersebut. Pipa sebelah barat flesibilitas nya mencapai 0,009 lebih kecil dari yang distandarkan maka kondisi pipa tidak mengalami pemuaian.

\section{DAFTAR PUSTAKA}

1. ASME Code for Pressure Piping, B31.3, 1996, Process Piping, American Society of Mechanical Engineers, New York, Including ASME B31.3a-1996.

2. API Standard 661, 1997, Air-Cooled Heat Exchangers for General Refinery Services, American Petroleum Institute, Washington, DC.

3. Arismunandar, Wiranto. Penggerak Mula, Turbin. Bandung:ITB. 1982.
4. Kannapan, Sam. 1986. Instroduction to Pipe Stress Analysis. Jhon Wiley And Sons, Inc., U.S.A.

5. Electric, General. Steam Turbin Operation Training Manual Volume I PLN Sumitomo Tambak Lorok Indonesia. USA : General Electric Company. 1997.

6. Dietzel, Fritz. Turbin Pompa dan Kompresor. Jakarta:Erlangga. 1994.

7. W.M. Kays and A.L. London, Compact Heat Exchangers, Second Edition, McGraw-Hill Book Co., New York, 1964.

8. B.R. Munson, D.F. Young, T.H. Okiishi, Fundamentals of Fluids Mechanics, Edisi 4, Jhon Wiley \& Sons, Inc, New York, 2002.

9. Burlian, F. Ghafara, A. Maret 2013, "Perancangan Ulang Heat Recovery Steam Generator dengan Sistem Dual Pressure Melalui Pemanfaatan Gas Buang Sebuah Turbin Gas Berdaya 160 MW". Jurnal Rekayasa, Volume 13, No. 1. ISSN. $233 \mathrm{H}-7089$.

10. Holman, E. Jasjfi, Terjemahan. Perpindahan Kalor, Penerbit Erlangga 1988. 
Infomatek Volume 20 Nomor 2 Desember 2018 : 101 - 106

11. H. Abdurachim, Analisa Kegagalan pada Pipa LP Evaporator HRSG 1.3, laporan kerja LAPI ITB-PT. Indonesia

Power, LAPI ITB, 2013. 